\title{
Methylation of the genes ROD1, NLRC5, and HKR1 is associated with aging in Hainan centenarians
}

\author{
Qian Zeng, Xiaoping Chen, Chaoxue Ning, Qiao Zhu, Yao Yao, Yali Zhao ${ }^{*}$ and Fuxin Luan ${ }^{*}$
}

\begin{abstract}
Background: Human aging is a hot topic in biology, and it has been associated with DNA methylation changes at specific genomic sites. We aimed to study the changes of DNA methylation at a single-CpG-site resolution using peripheral blood samples from centenarians.

Methods: Using Illumina 450 K Methylation BeadChip microarray assays, we carried out a pool-based, epigenome-wide investigation of DNA methylation of blood samples from 12 centenarians and 12 healthy controls. Differentially methylated cytosine-phosphate-guanosine $(\mathrm{CpG})$ sites were selected for further pyrosequencing analysis of blood samples from 30 centenarians and 30 healthy controls.

Result: We identified a total of 31 high-confidence $\mathrm{CpG}$ sites with differential methylation profiles between the groups: 9 (29\%) were hypermethylated and 22 (71\%) were hypomethylated in centenarians. It was also found that hypermethylation of HKR1 and hypomethylation of ROD1 and NLRC5 genes strongly correlated with age in centenarians.
\end{abstract}

Conclusion: Our results indicate that the methylation profile combination of HKR1, ROD1, and NLRC5 could be a promising biomarker for aging in Hainan centenarians.

Keywords: DNA methylation, Aging, ROD1, NLRC5, HKR1

\section{Background}

Improvements in living conditions have meant that the average life expectancy of human beings is rising. Indeed, it has increased by approximately 10 years over the last century [1]. On the other hand, aging has attracted more and more attention. Aging is a very complex trait, involving environmental, genetic, and stochastic factors [2], and, in recent decades, has been a focus for scientists worldwide. Centenarian cohort is one of the most valuable models to study the mechanisms involved in human aging [3]. Centenarians are considered to have reached the extreme limits of the human life span, but still remain in relatively good health maintaining physiological functions and avoid succumbing to common fatal diseases $[4,5]$. Hainan, with a centenarian density of 21.46 per 100,000 people, is one of the most longevous regions in China. We managed to recruit 42

\footnotetext{
*Correspondence: zhaoyl301@163.com; baisui301@163.com Hainan branch of PLA General Hospital, Sanya 572000, China
}

centenarians and 42 healthy adult controls from Hainan Province, and performed complete physical examinations on all subjects.

Human aging has largely been driven by extrinsic improvements to living conditions, including improved diet and reduced disease prevalence, as well as by both genetic and epigenetic factors [6-8]. Here, we evaluated the crucial role of epigenetic modification in gene regulation, with a particular focus on DNA methylation [9-11]. As early as 1975, it was proposed that DNA methylation could regulate gene activity. Methylation occurs primarily at $\mathrm{CpG}$ dinucleotides, which can form $\mathrm{CpG}$ islands containing an above average CpG density $[12,13]$. DNA methylation has been shown to regulate gene expression and plays a role in alternative silencing [14, 15]. Furthermore, $\mathrm{CpG}$ islands overlap the transcription start sites (TSSs) of a majority of human genes, and TSS methylation is known to prevent transcriptional initiation 
$[16,17]$. Yet, the role of methylation in the gene body is less clear. Recent studies have demonstrated the presence of aging-associated CpG sites, which were either hypermethylated or hypomethylated [18-21]. Human genomic methylation has recently been advanced by utilization of the Illumina Human Methylation $450 \mathrm{~K}$ BeadChip Array (450 K array), which includes probes spanning $99 \%$ of human genes, evenly distributed across the genome. This system can detect the shores and shelves of $\mathrm{CpG}$ islands and non-CpG islands, as well as methylation sites in promoter regions, gene bodies, and untranslated regions (UTRs) [22-24].

In the present study, we aimed to identify DNA methylation sites by exploring differences in genomic methylation between centenarians and healthy controls. Using microarray technology and pyrosequencing and a pool-based strategy, we performed an epigenome-wide investigation of DNA methylation in a total of 42 centenarians from Hainan Province. We found that ROD1, NLRC5, and HKR1 genes were differentially methylated between centenarians and healthy controls, suggesting they might be associated with aging in Hainan centenarians.

\section{Methods}

\section{Subjects}

This study formed part of the "Health Investigation and Longevous Mechanism Study on Centenarians in Hainan Province" project, conducted between 2014 and 2016. The subject consisted of 42 centenarians (male: 15, female: 27; Han nationality) and 42 healthy adult controls (male: 18, female: 24; Han nationality). Characteristic information on centenarians and healthy controls is described in Table 1. Significant differences in characteristic information between centenarians and healthy controls are age-related. Healthy controls were excluded if they were suffering from known infectious diseases, or if they had a history of cancer, cardiovascular disease, or autoimmune disease. Neither the centenarians nor the healthy controls included in this study had any

Table 1 Physical characteristics measures of the centenarians $(n=42)$ and healthy controls $(n=42)$

\begin{tabular}{|c|c|c|}
\hline Characteristics & Centenarians $(n=42)$ & Healthy controls $(n=42)$ \\
\hline Age (yrs) * & $102.2 \pm 0.3$ & $49.1 \pm 0.8$ \\
\hline Height $(\mathrm{cm}) *$ & $148.3 \pm 1.4$ & $166.2 \pm 1.2$ \\
\hline $\operatorname{Mass}(\mathrm{kg}) *$ & $41.7 \pm 1.3$ & $62.0 \pm 1.1$ \\
\hline $\mathrm{BMI}\left(\mathrm{kg} / \mathrm{m}^{-2}\right) *$ & $18.9 \pm 0.5$ & $22.4 \pm 0.2$ \\
\hline waist circumference $(\mathrm{cm})$ & $76.8 \pm 1.7$ & $79.8 \pm 0.9$ \\
\hline Hip circumference $(\mathrm{cm}) *$ & $86.0 \pm 1.2$ & $91.9 \pm 0.5$ \\
\hline
\end{tabular}

Significant difference from centenarians indicated by * $(p<0.05)$. Data are mean \pm SEM infections, and neither group had received any vaccinations in the 15 days prior to the collection of blood samples. Peripheral blood samples were collected by morning fasting. Additional informed consent was obtained from all individual participants for whom identifying information is included in this article.

\section{Genomic DNA extraction}

Peripheral blood samples were collected in EDTAtreated collection tubes by experienced nurses during a home visit, and then transferred to the Hainan branch of PLA General Hospital laboratory for processing within $4 \mathrm{~h}$. Genomic DNA was extracted using a QIAamp DNA Mini kit (Qiagen, Germany), according to the manufacturer's instructions for the Spin Procedure. DNA was eluted in $60 \mu \mathrm{L}$ of $\mathrm{AE}$ elution buffer, and then stored at $-20{ }^{\circ} \mathrm{C}$ until use. The concentration and purity of DNA samples were assessed using a Qubit dsDNA HS Assay kit (Invitrogen, Eugene, OR, USA) according to the manufacturer's instructions, and $1 \%$ agarose gel electrophoresis.

\section{Microarray analysis}

Infinium Human Methylation 450BeadChips (Illumina) were used to assay genome-wide DNA methylation. The microarray chip contained 485,577 locusspecific CpG sites. Bisulfite conversion of DNA samples was done using the EZ DNA Methylation Kit (Zymo Research). Microarrays were normalized by methylumi Bioconductor [25-27]. Differentially methylated CpGs were selected using an algorithm in IMA Bioconductor. Probes were used in the analysis, after excluding those with a $P$ value higher than 0.01 in more than $25 \%$ of the samples, those in chromosome $\mathrm{Y}$ and SNP sites. In this study, we assessed the meandifference $\beta$-value $(\Delta \beta)$ between the two sample groups for each $\mathrm{CpG}$ site. The Illumina platform shows a significant dye bias (probe-type design differences) in the two channels which will lead to bias in the estimates of Beta on the GoldenGate platform. Therefore, some normalization was required. Basically, it looks at the median intensities in the methylated and unmethylated channels (each measured in one color on the GoldenGate platform) at very low and very high beta values and sets these medians equal. And then a quantile approach was used to eliminate the batch effects among every microarray. In microarray data analysis, false positives are loci that are found to be statistically different between conditions. However, clinical samples may have relatively high individual heterogeneity, and the amount of samples is not enough. If we use $p$-values for multiple test corrections, it eliminated the false positive, but may have a certain false negative at the same time. Therefore, 
we considered a probe as differentially methylated if the absolute $\Delta \beta$ was higher than 0.2 and the statistical test was significant $(p$ value $<0.01$ ) with wilcox $[28-30]$.

\section{Bioinformatic analysis}

As described above, genome-wide DNA methylation was assessed using a pool-based approach, in which the $\beta$-value for each probe represents the average methylation level of all samples in the pool. To identify differentially methylated probes (DMPs), it was assumed that the genome-wide methylation conformed to a Gaussian model [31], and then differences in methylation between the two data sets were calculated. Gene ontology (GO) and Kyoto Encyclopedia of Genes and Genomes (KEGG) pathway enrichment analyses were conducted using the DAVID database. GO terms and KEGG information were downloaded from the Bioconductor site.

\section{Bisulfite pyrosequencing analysis}

Based on the results of the methylation microarrays, three CpG sites were selected for further pyrosequencing analysis, using blood samples from 30 centenarians and 30 healthy controls. Bisulfite modification of 1-2 $\mu \mathrm{g}$ DNA was performed using an EpiTect Bisulfite kit (Qiagen) according to the manufacturer's instructions. Next, bisulfite pyrosequencing primers were designed using PyroMark Assay Design software version 2.0 (Qiagen). Sequencing reactions and methylation level quantification were then performed using the PyroMark Q96 ID system and

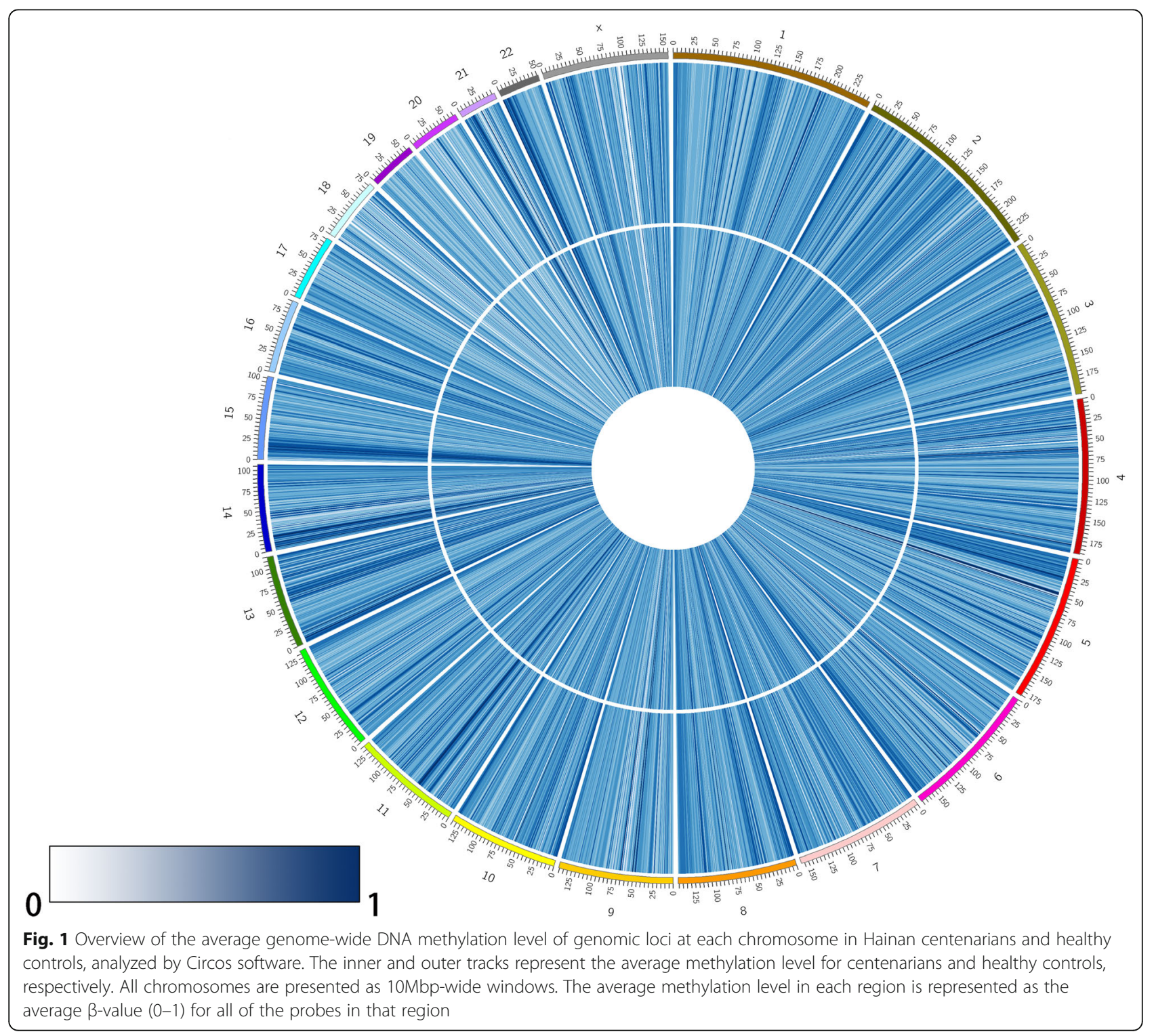


software (Qiagen), respectively. Pyrosequencing primer sequences are presented in additional file 1.

\section{Statistical analyses}

SPSS software version 17.0 (SPSS Inc., Chicago, IL, USA) was only used for the pyrosequencing analyses. Differences between two independent groups were compared using Student's $t$-tests and $P<0.01$ was used to define statistical significance.

\section{Results}

Differential analysis of the DNA methylomes of Hainan centenarians and healthy controls

Using microarray and pyrosequencing methods, we performed an analysis of DNA methylation patterns in

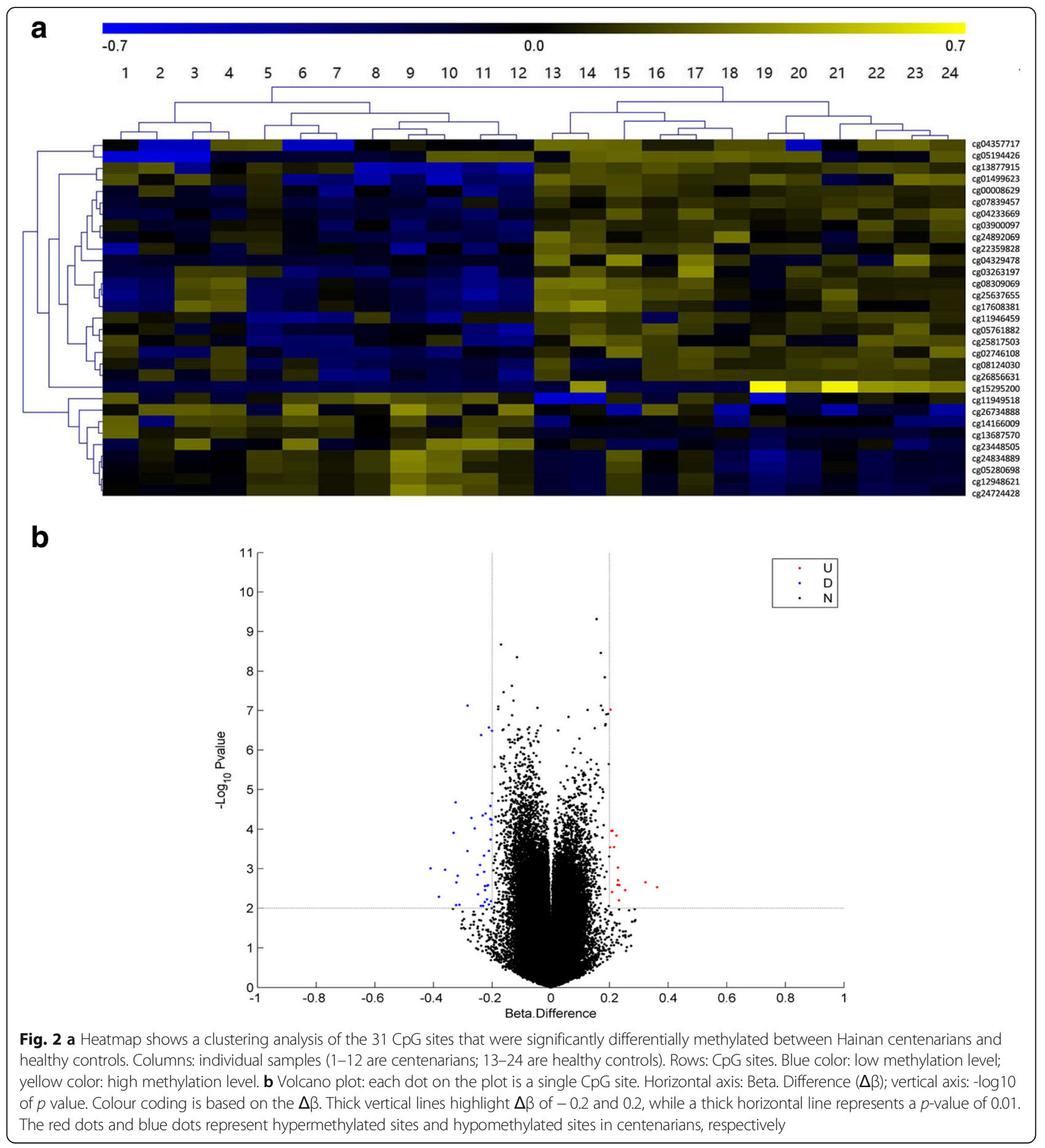


centenarians and healthy controls from Hainan Province. An overview of the genome-wide methylation profiles for both groups is shown in Fig. 1. Different patterns of methylation between centenarians and healthy controls were observed at the majority of methylation loci, indicating that DNA methylation-based epigenetic profiles might be significant in aging. Having discovered these differences in DNA methylation, we then searched for individual DMPs. To do this, we performed a pooledtest to analyze the average methylation level at all of the CpG loci in the centenarian and healthy control groups. In total, 31 DMPs were identified using the criteria
$P<0.01$ and $|\Delta \beta|>0.2$, as shown in Fig. 2a and b. In this analysis, $\Delta \beta>0.2$ and $\Delta \beta<-0.2$ refer to loci that were hypermethylated or hypomethylated in centenarians relative to healthy controls, respectively. Among the 31 DMPs identified, 9 were hypermethylated $\mathrm{CpG}$ sites and 22 were hypomethylated CpG sites (Table 2).

\section{GO and KEGG functional enrichment analysis of differentially methylated genes}

Our results showed that the 31 identified significantly differentially methylated sites described above could be mapped to 23 different genes. We performed GO term

Table 2 List of 31 CpG sites showing significant differences in methylation between centenarians and healthy controls

\begin{tabular}{|c|c|c|c|c|c|c|}
\hline Probe ID & $P$ Value & FDR & $\Delta \beta$ & Gene & Region & Chromosome \\
\hline \multicolumn{7}{|c|}{ Hypermethylated genes } \\
\hline $\operatorname{cg} 24724428$ & 9.49E-08 & 2.94E-03 & 0.203271068 & ELOVL2 & TSS1500 & 6 \\
\hline cg23448505 & 1.09E-04 & 6.99E-02 & 0.210419612 & HKR1 & $5^{\prime} \mathrm{UTR}$ & 19 \\
\hline $\operatorname{cg} 14166009$ & 1.10E-04 & 7.04E-02 & 0.206571283 & HKR1 & TSS1500 & 19 \\
\hline $\operatorname{cg} 13687570$ & $1.46 \mathrm{E}-04$ & 7.97E-02 & 0.224156561 & HKR1 & TSS1500 & 19 \\
\hline $\operatorname{cg} 26734888$ & $2.82 \mathrm{E}-04$ & $1.08 \mathrm{E}-01$ & 0.215848099 & HKR1 & TSS1500 & 19 \\
\hline $\operatorname{cg} 12948621$ & $2.86 \mathrm{E}-04$ & 1.09E-01 & 0.201660605 & HKR1 & TSS200 & 19 \\
\hline $\operatorname{cg} 24834889$ & $9.41 \mathrm{E}-04$ & $1.79 \mathrm{E}-01$ & 0.229230299 & HKR1 & TSS200 & 19 \\
\hline cg05280698 & $1.95 \mathrm{E}-03$ & $2.32 \mathrm{E}-01$ & 0.22951704 & HKR1 & TSS200 & 19 \\
\hline cg11949518 & $2.54 \mathrm{E}-03$ & $2.52 \mathrm{E}-01$ & 0.227662305 & RPTOR & Body & 17 \\
\hline \multicolumn{7}{|c|}{ Hypomethylated genes } \\
\hline cg07839457 & $7.52 \mathrm{E}-08$ & 2.94E-03 & -0.283566443 & NLRC5 & TSS1500 & 16 \\
\hline cg04233669 & $2.70 \mathrm{E}-07$ & 4.49E-03 & -0.210848478 & LOC153328 & Body & 5 \\
\hline cg00008629 & 4.19E-07 & $5.21 \mathrm{E}-03$ & -0.237495141 & ROD1 & $5^{\prime} U T R$ & 9 \\
\hline cg24892069 & $2.60 \mathrm{E}-05$ & 2.07E-01 & -0.205487552 & NRP1 & TSS1500 & 10 \\
\hline cg01499623 & 4.50E-05 & 4.55E-02 & -0.232050941 & SMU1 & Body & 9 \\
\hline cg22359828 & 5.49E-05 & 5.01E-02 & -0.206320371 & CACNA1E & Body & 1 \\
\hline cg03930097 & 7.66E-05 & $5.82 \mathrm{E}-02$ & -0.201870989 & HLA-DRA & Body & 6 \\
\hline cg04329478 & 9.57E-05 & $6.52 \mathrm{E}-02$ & -0.259320244 & LOC400696 & TSS200 & 19 \\
\hline cg17608381 & $1.24 \mathrm{E}-04$ & 7.37E-02 & -0.331606794 & $\mathrm{HLA}-\mathrm{A}$ & Body & 6 \\
\hline cg04357717 & $3.55 \mathrm{E}-04$ & $1.21 \mathrm{E}-01$ & -0.210909327 & ZPLD1 & Body & 3 \\
\hline cg11946459 & $3.56 \mathrm{E}-04$ & $1.21 \mathrm{E}-01$ & -0.283888936 & $\mathrm{HLA}-\mathrm{A}$ & Body & 6 \\
\hline cg13877915 & $8.02 \mathrm{E}-04$ & $1.68 \mathrm{E}-01$ & -0.241392036 & ZNF132 & TSS200 & 19 \\
\hline cg26856631 & 9.82E-04 & 1.81E-01 & -0.409805022 & LSM5 & 3'UTR & 7 \\
\hline cg25817503 & $1.20 \mathrm{E}-03$ & $1.95 \mathrm{E}-01$ & -0.227151237 & AFAP1 & Body & 4 \\
\hline cg08309069 & $1.43 \mathrm{E}-03$ & 2.07E-01 & -0.249630086 & $\mathrm{HLA}-\mathrm{C}$ & TSS1500 & 6 \\
\hline cg08124030 & 2.23E-03 & $2.41 \mathrm{E}-01$ & -0.321896757 & TM4SF1 & 1stExon & 3 \\
\hline cg05761882 & $2.59 \mathrm{E}-03$ & $2.53 \mathrm{E}-01$ & -0.213920774 & CAPN2 & Body & 1 \\
\hline cg15295200 & $5.13 \mathrm{E}-03$ & $3.14 \mathrm{E}-01$ & -0.381483294 & NMNAT3 & TSS1500 & 3 \\
\hline cg25637655 & 5.97E-03 & $3.28 \mathrm{E}-01$ & -0.217322003 & HLA-A & Body & 6 \\
\hline cg03263197 & $6.62 \mathrm{E}-03$ & 3.36E-01 & -0.203535875 & UBL4B & TSS1500 & 1 \\
\hline cg02746108 & $6.97 \mathrm{E}-03$ & $3.40 \mathrm{E}-01$ & -0.225251292 & AGAP1 & Body & 2 \\
\hline cg05194426 & 8.66E-03 & 3.59E-01 & -0.230652944 & CYP2E1 & Body & 10 \\
\hline
\end{tabular}


Table 3 Analysis of significantly hypermethylated differentially methylated probes (DMPs)

\begin{tabular}{|c|c|c|c|}
\hline GO ID & Description & $P$ Value & Genes \\
\hline \multicolumn{4}{|c|}{ Biological process } \\
\hline GO:0048002 & $\begin{array}{l}\text { antigen processing } \\
\text { and presentation } \\
\text { of peptide antigen }\end{array}$ & $4.27 \mathrm{E}-04$ & $\begin{array}{l}\text { HLA-A, HLA-C, } \\
\text { HLA-DRA }\end{array}$ \\
\hline GO:0019882 & $\begin{array}{l}\text { antigen processing } \\
\text { and presentation }\end{array}$ & $3.70 \mathrm{E}-03$ & $\begin{array}{l}\text { HLA-A, HLA-C, } \\
\text { HLA-DRA }\end{array}$ \\
\hline GO:0002474 & $\begin{array}{l}\text { antigen processing } \\
\text { and presentation of } \\
\text { peptide antigen via } \\
\text { MHC class I }\end{array}$ & $1.86 \mathrm{E}-02$ & HLA-A, HLA-C \\
\hline \multicolumn{4}{|c|}{ Cellular component } \\
\hline GO:0042611 & MHC protein complex & $1.71 \mathrm{E}-03$ & $\begin{array}{l}\text { HLA-A, HLA-C, } \\
\text { HLA-DRA }\end{array}$ \\
\hline GO:0042612 & $\begin{array}{l}\text { MHC class I protein } \\
\text { complex }\end{array}$ & $3.02 \mathrm{E}-02$ & HLA-A, HLA-C \\
\hline GO:0005626 & insoluble fraction & 5.95E-02 & $\begin{array}{l}\text { ELOVL2, HLA-C, } \\
\text { CYP2E1, CAPN2 }\end{array}$ \\
\hline GO:0044459 & $\begin{array}{l}\text { plasma membrane } \\
\text { part }\end{array}$ & $7.76 \mathrm{E}-02$ & $\begin{array}{l}\text { HLA-A, HLA-C, } \\
\text { CACNA1E, } \\
\text { TM4SF1, } \\
\text { AFAP1, } \\
\text { HLA-DRA }\end{array}$ \\
\hline GO:0005886 & plasma membrane & 8.86E-02 & $\begin{array}{l}\text { NRP1, HLA-A, } \\
\text { HLA-C, CACNA1E, } \\
\text { TM4SF1, CAPN2, } \\
\text { AFAP1, } \\
\text { HLA-DRA }\end{array}$ \\
\hline GO:0031224 & intrinsic to membrane & 8.97E-02 & $\begin{array}{l}\text { ZPLD1, NRP1, } \\
\text { ELOVL2, HLA-A, } \\
\text { HLA-C, CACNA1E, } \\
\text { TM4SF1, } \\
\text { LOC153328, } \\
\text { CYP2E1, HLA-DRA }\end{array}$ \\
\hline \multicolumn{4}{|c|}{ Molecular function } \\
\hline GO:0032393 & $\begin{array}{l}\text { MHC class I receptor } \\
\text { activity }\end{array}$ & 2.07E-02 & HLA-A, HLA-C \\
\hline GO:0032395 & $\begin{array}{l}\text { MHC class II receptor } \\
\text { activity }\end{array}$ & $2.31 \mathrm{E}-02$ & HLA-C, HLA-DRA \\
\hline
\end{tabular}

and KEGG pathway enrichment analyses to elucidate the biological functions of these genes, using the $\mathrm{R}$ package GOstats described previously [32]. The biological processes, molecular functions, and cellular components that were enriched in the GO analysis of longevity-associated DMP-containing genes (DMGs) are summarized in Table 3. In total, 3 biological processes, 6 cellular components, and 2 molecular function terms were enriched in the 23 DMGs. The enriched biological functions, such as antigen processing and presentation of peptide antigen (GO: 0048002) are associated with immune system function. Furthermore, enriched cellular components include major histocompatibility complex (MHC) protein complex and insoluble fraction (GO: 0042611 and GO: 0005626, respectively). MHC receptor activity, class I and II (GO: 0032393 and GO: 0032395, respectively), are enriched molecular functions in the DMG subset.

KEGG analysis revealed the enrichment of only several pathways in the DMG subset (Table 4), with the most significantly enriched biological pathways being graft-versus-host disease (KEGG: 05332) and allograft rejection (KEGG: 05330).

\section{Changes in ROD1, NLRC5 and HKR1 DNA methylation in centenarians}

The CpGs associated with aging were not uniformly distributed across chromosomes, CpG islands, or genes; significantly differentially methylated sites were overrepresented on chromosomes 3, 6, 9, and 19 (Table 2).

The gene locations of the DMPs were assessed, and defined as follows: $1500 \mathrm{bp}$ upstream of the TSS (TSS1500), 200 bp upstream of the TSS (TSS200), the 5'-UTR, exon 1, the gene body (encompassing all exons except exon 1), and the 3'-UTR. Some of the enriched DMPs were located within the gene body, but the role of methylation within the gene body is less clear. DNA methylation of promoter regions is a repressive epigenetic mark that regulates gene expression. The three most significantly hypermethylated genes in the centenarian group were ELOVL fatty acid elongase 2 (ELOVL2; ID cg24724428), histidine kinase rhodopsins 1 (HKR1; ID cg23448505; ID cg14166009; ID

Table 4 KEGG pathway enrichment analysis of significantly differentially methylated probes (DMPs)

\begin{tabular}{llll}
\hline KEGG ID & Description & $P$ Value & Genes \\
\hline KEGG:05332 & Graft-versus-host disease & $1.18 \mathrm{E}-03$ & HLA-A, HLA-C, HLA-DRA \\
KEGG:05330 & Allograft rejection & $1.48 \mathrm{E}-03$ & HLA-A, HLA-C, HLA-DRA \\
KEGG:04940 & Type I diabetes mellitus & $1.91 \mathrm{E}-03$ & HLA-A, HLA-C, HLA-DRA \\
KEGG:05320 & Autoimmune thyroid disease & $2.92 \mathrm{E}-03$ & HLA-A, HLA-C, HLA-DRA \\
KEGG:05416 & Viral myocarditis & $3.50 \mathrm{E}-03$ & HLA-A, HLA-C, HLA-DRA \\
KEGG:04612 & Antigen processing and presentation & $6.15 \mathrm{E}-03$ & HLA-A, HLA-C, HLA-DRA \\
KEGG:05166 & HTLV-I infection & $6.64 \mathrm{E}-03$ & NRP1, HLA-A, HLA-C, HLA-DRA \\
\hline
\end{tabular}


Table $\mathbf{5}$ List of CpG sites showing significant differences between Hainan centenarians and healthy controls

\begin{tabular}{llll}
\hline Site & Gene & $T$ & $P$ \\
\hline cg00008629 & ROD1 & -6.388 & $<0.001$ \\
cg07839457 & NLRC5 & -12.779 & $<0.001$ \\
cg26734888 & HKR1 & 3.363 & 0.001 \\
\hline
\end{tabular}

cg13687570; ID cg26734888; ID cg12948621; ID cg24834889; IDcg05280698) and regulatory associated protein of MTOR complex 1 (RPTOR; ID cg11949518). The CpG islands in the ELOVL2 gene was located within the gene promoter (TSS1500), HKR1 gene was located within TSS1500, TSS200 and 5'-UTR, while RPTOR genes were located within the gene body. Previous studies demonstrated that methylation of a $\mathrm{CpG}$ island within the ELOVL2 gene strongly correlates with age; indeed such methylation was declared a novel epigenetic marker for aging [33, 34]. Furthermore, seven gene sites (ID cg23448505; ID cg14166009; ID cg13687570; ID cg26734888; ID cg12948621; ID cg24834889; IDcg05280698) belong to the same gene(HKR1), therefore, we chose one of HKR (ID cg26734888) to pyrosequence in a large sample set. The three most significantly hypomethylated genes in the centenarians were NLR family CARD domain containing 5 (NLRC5; ID cg07839457), regulator of differentiation 1 (ROD1; ID cg00008629) and LOC153328 (ID cg04233669). The CpG islands in the NLRC5 gene was located TSS1500; ROD1 gene was located 5'UTR, while LOC153328 gene was located within the gene body. It has been reported that the methylation level of CpGs within the coding region can regulate gene transcription [35]. To confirm these observations, we chose NLRC5 (ID cg07839457) and ROD1 (ID cg00008629) genes to pyrosequence in a large sample set. In total, 60 peripheral blood samples (30 samples from each group) underwent pyrosequencing. As expected, significant differences in the level of methylation at the sites cg00008629 (ROD1), cg07839457 (NLRC5), and cg26734888 (HKR1) were observed between Hainan centenarians and healthy controls (Table 5 and Fig. 3). Using a regression-based approach, we further analyzed the DNA methylation data based on cell type compositions [36]. Our further analyses indicated that the differences in the level of methylation of cg00008629 (ROD1), cg07839457 (NLRC5), and cg26734888 (HKR1) sites were significant $(p$ value $<0.05)$ between centenarians and healthy controls (Table 6).

\section{Discussion}

In our current study, we analyzed theDNA methylation of blood samples collected from centenarians and healthy controls in Hainan province, China. In summary, we found 31 DMPs using a $450 \mathrm{~K}$ array. Furthermore, our pyrosequencing analysis showed that methylation level at three of CpGs, ROD1, NLRC5, and HKR1 strongly correlates with aging in centenarians.

Our results also indicate that 31 high-confidence CpG sites with differential methylation profiles between the groups; 9 (29\%) were hypermethylated and $22(71 \%)$ were hypomethylated in centenarians. KEGG pathway analysis showed that the most significantly

\section{$\square$ Healthy controls $\square$ Centenarians}

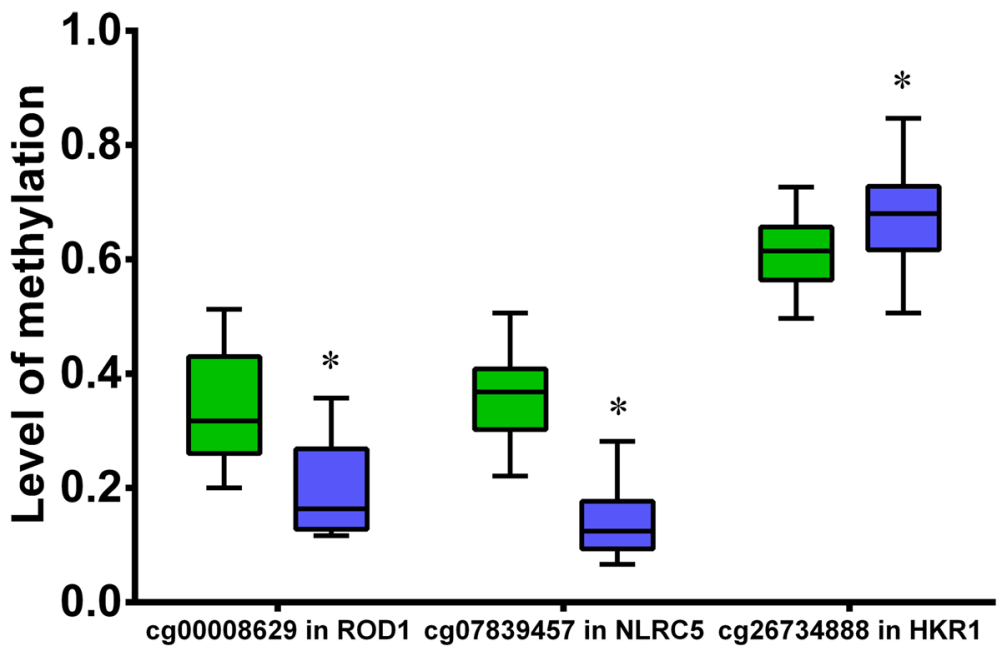

Fig. 3 The level of methylation at the indicated CpG sites in centenarians (blue boxes) and healthy controls (green boxes). The boxes represent the 25 th to the 75 th centiles, and solid lines represent the median value for each sample. Error bars represent $95 \%$ confidence intervals. ${ }^{*} p<0.05$ indicated the significant different between healthy controls and centenarians 
Table 6 List of 3 CpG sites showing significant differences in methylation between centenarians and healthy controls after adjusted for cell type composition in DNA methylation data

\begin{tabular}{llll}
\hline Site & Gene & $P$ (before cell type correction) & $P$ (after cell type correction) \\
\hline cg00008629 & ROD1 & $4.19 \mathrm{E}-07$ & $3.48 \mathrm{E}-02$ \\
cg07839457 & NLRC5 & $7.52 \mathrm{E}-08$ & $1.99 \mathrm{E}-02$ \\
cg26734888 & HKR1 & $2.82 \mathrm{E}-04$ & $4.46 \mathrm{E}-02$ \\
\hline
\end{tabular}

enriched biological pathways being graft-versus-host disease and allograft rejection. Further studies are needed to study how these pathways relate to the aging exhibited by centenarians.

The ROD1 gene was discovered to be hypomethylated in centenarians. This gene encodes an RNAbinding protein that binds preferentially to poly $(\mathrm{G})$ and poly(U) sequences in vitro, and was initially regarded as an inhibitor of differentiation [37]. Several ROD1 transcriptional variants, encoding different isoforms, have been identified. In addition, ROD1 was recently found to be a member of the heterogeneous nuclear ribonucleoprotein family, which regulate the alternative splicing of pre-RNA, and can thus modulate gene expression by repressing the expression of exons in a tissue specific manner [38, 39]. Further, ROD1 binding to C-terminal peptide was strongly inhibited by synthetic RNA and weakly inhibited by a synthetic phosphorylated peptide designed to mimic the C-terminal domain of RNA polymerase II. Interestingly, ROD1 expression and knockdown experiments suggest a role in the regulation of C-terminal peptide mitogenic activity [40], suggesting a potential correlation between hypomethylation of ROD1 gene and aging in centenarians.

NLRC5, a member of the NOD-like receptor gene family and widely expressed in tumor tissues, is a key transcriptional regulator of $\mathrm{MHC}$ class I molecules [41, 42]. Cancers can escape immune surveillance by reducing the expression of MHC class I molecules. NLRC5, an important regulator of innate immune responses, may affect patient survival by regulating this immune evasion via MHC class I molecules. NLRC5 could therefore be exploited to restore tumor immunogenicity and to stimulate protective antitumor immunity [43]. While the role of NLRC5 in both innate and adaptive immune signaling is well established, its function in inflammation remains poorly understood. The regulation of NF- $\mathrm{kB}$ activation is crucial for many biological functions, and NF-kB dysregulation is associated with immune deficiency, infectious disease, inflammation, and cancer $[44,45]$. NLRC5 has been reported to inhibit NF- $\mathrm{kB}$ activation by interacting with $\mathrm{IKK}-\alpha /-\beta$ and blocking its phosphorylation [46]. To date, there have been no reports which implicate NLRC5 in aging, however, we found that NLRC5 was hypomethylated in centenarians. Methylation of the NLRC5 is negatively correlated with NLRC5 expression in many cells $[47,48]$. It is possible that this NLRC5 hypomethylation is involved in aging through the regulation of various biological pathways.

In contrast to ROD1 and NLRC5, HKR1 was hypermethylated in centenarians. HKR1 encodes Krueppelrelated zinc finger protein 1, a member of the GLI-Kruppel zinc finger family that is important for gene regulation [49]. The HKR1 protein possesses a serine/threonine-rich domain, and a $\mathrm{Ca}^{2+}$-binding consensus sequence within its cytoplasmic domain. Recently, HKR1 mRNA expressions were found to be higher in lung cancer tissues than in normal lung tissues, and HKR1 may be involved in the regulation of a signaling pathway involved in lung cancer progression [50]. Although the physiological roles of HKR1 remain unclear, HKR1 knockout is lethal, indicating that this gene is essential for survival. Further research is needed to fully understand the significance of HKR1 hypermethylation in centenarians and its effect on aging.

However, it is worth mentioning that peripheral blood is a heterogeneous collection of different cell types, each with a very different DNA methylation profile. Differences in the relative proportions of these components may contribute to differences in DNA methylation [51-53]. To identify the potential effect of cellular proportions in the DNA methylation differentiation, we used a regression-based approach to adjusting for cell type composition in DNA methylation data. Our results indicated that the methylation cg00008629 (ROD1), cg07839457 (NLRC5), and cg26734888 (HKR1) were also found significant differences between centenarians and healthy controls.

To our knowledge, the association between the genes ROD1, NLRC5, and HKR1 and aging have not been previously reported. We here found significantly different levels of DNA methylation at the ROD1, NLRC5, and HKR1 genes in centenarians and healthy controls. Our findings implicate that these genes may play important roles in aging via the regulation of various biological pathways and could be used as biomarker genes for aging. 


\section{Conclusions}

In summary, we present a comprehensive comparison of genomic methylation in centenarians and healthy controls residing in Hainan Province. We report an epigenetic signature consisting of three genes, which can be used to estimate aging from blood samples. Changes to the methylation of $\mathrm{CpG}$ islands, namely, hypomethylation within the ROD1 and NLRC5 and hypermethylation within HKR1 genes, are possibly correlated with aging in centenarians. While further studies are required to understand the mechanisms and signaling pathways through which ROD1, NLRC5, and HKR1 methylation affect aging, the methylation of these genes constitutes a signature that could be used to evaluate aging. The combination of ROD1, NLRC5, and HKR1 gene methylation is therefore a potential novel biomarker for aging.

\section{Additional file}

Additional file 1: "Pyrosequencing primer sequences of three sites". This file contains detailed description of pyrosequencing primer sequences. (DOCX $12 \mathrm{~kb})$

\section{Abbreviations}

CpG: cytosine-phosphate-guanosine; DMG: DMP-containing genes; DMP: Differentially methylated probe; ELOVL2: ELOVL fatty acid elongase 2; GO: Gene ontology; HKR1: Histidine kinase rhodopsins 1; KEGG: Kyoto Encyclopedia of Genes and Genomes; MHC: Major histocompatibility complex; NLRC5: NLR family CARD domain containing 5; ROD1: Regulator of differentiation 1; TSS: Transcription start sites; UTR: Untranslated regions

\section{Acknowledgements}

We appreciate all the participants of the Hainan Centenarian Study for their continued cooperation. We thank Hanqi Yin (Guangdong Longsee biomedical corporation) for guidance on data analysis.

\section{Funding}

This study was funded by Key research funding of Hainan (grant nos. 16A200143 and 14A110069), and Key Research and Development Project of Hainan (grant nos. ZDYF2016135 and ZDYF2017095). There is no role of the funding body in the design of the study and collection, analysis, and interpretation of data and in writing the manuscript.

\section{Availability of data and materials}

The datasets used and analyzed during the current study are available from the corresponding author on reasonable request.

\section{Authors' contributions}

QZ designed the study and drafted the manuscript. XPC and QZH conducted experiments. CXN performed statistical analyses. YY prepared the samples. YLZ and FXL conceived the study, participated in its design and coordination, and helped to draft the manuscript. The authors declare that they have no conflict of interest. All authors have read and approved the final manuscript.

\section{Ethics approval and consent to participate}

Prior to investigation and physical examination, we have got the consent from the participants or from their family members such as sons and daughter-in-laws. If the participants could not sign their names because of illiteracy or being cognitive-impaired, their names were signed by their direct relatives after the consent of the participants. The Ethics Committee of the Hainan branch of the Chinese People's Liberation Army General Hospital (Sanya, Hainan) approved the study protocol (No. of serial: $301 \mathrm{hn11201601).}$

\section{Consent for publication}

Not applicable.

\section{Competing interests}

On behalf of all authors, the corresponding author states that there is no conflict of interest.

\section{Publisher's Note}

Springer Nature remains neutral with regard to jurisdictional claims in published maps and institutional affiliations.

Received: 22 August 2017 Accepted: 25 January 2018

Published online: 02 February 2018

\section{References}

1. Vaupel JW. Biodemography of human ageing. Nature. 2010;464(7288):536-42.

2. Singh R, Kolvraa S, Rattan SI. Genetics of human longevity with emphasis on the relevance of HSP70 as candidate genes. Front Biosci. 2007;12:4504-13.

3. Franceschi $\mathrm{C}$, Bonafe $\mathrm{M}$. Centenarians as a model for healthy aging. Biochem Soc Trans. 2003;31(2):457-61.

4. Brooks-Wilson AR. Genetics of healthy aging and longevity. Hum Genet 2013;132(12):1323-38.

5. He YH, Zhang YX, Yang LQ, Liao XP, Zhang QY, Cai WW, Kong QP. Assessment of the health status of centenarians in the south of China: a cross-sectional study. J Am Geriatr Soc. 2014;62(7):1402-4.

6. lannitti T, Palmieri B. Inflammation and genetics: an insight in the centenarian model. Hum Biol. 2011:83(4):531-59.

7. Browner WS, Kahn AJ, Ziv E, Reiner AP, Oshima J, Cawthon RM, Hsueh WC, Cummings SR. The genetics of human longevity. Am J Med. 2004:117(11):851-60.

8. Vijg J, Suh Y. Genome instability and aging. Annu Rev Physiol. 2013;75:645-68.

9. Xiao FH, He YH, Li QG, Wu H, Luo LH, Kong QP. A genome-wide scan reveals important roles of DNA methylation in human longevity by regulating age-related disease genes. PLoS One. 2015;10(3):e0120388.

10. Xiao FH, Kong QP, Perry B, he YH. progress on the role of DNA methylation in aging and longevity. Brief Funct Genomics. 2016:15(6):454-9.

11. Kaplow IM, JL MI, Mah SM, McEwen LM, Kobor MS, Fraser HB. a pooling-based approach to mapping genetic variants associated with DNA methylation. Genome Res. 2015;25(6):907-17.

12. Riggs AD. X inactivation, differentiation, and DNA methylation. Cytogenet Cell Genet. 1975;14(1):9-25.

13. Holliday R, Pugh JE. DNA modification mechanisms and gene activity during development. Science. 1975;187(4173):226-32.

14. Watt F, Molloy PL. Cytosine methylation prevents binding to DNA of a HeLa cell transcription factor required for optimal expression of the adenovirus major late promoter. Genes Dev. 1988;2(9):1136-43.

15. Nan X, Campoy FJ, Bird A. MeCP2 is a transcriptional repressor with abundant binding sites in genomic chromatin. Cell. 1997;88(4):471-81.

16. Illingworth RS, Bird AP. CpG islands-'a rough guide. FEBS Lett. 2009; 583(11):1713-20.

17. Deaton AM, Bird A. CpG islands and the regulation of transcription. Genes Dev. 2011:25(10):1010-22.

18. Fraga MF, Ballestar E, Paz MF, Ropero S, Setien F, Ballestar ML, Heine-Suner D, Cigudosa JC, Urioste M, Benitez J, et al. epigenetic differences arise during the lifetime of monozygotic twins. Proc Natl Acad Sci U S A. 2005; 102(30):10604-9.

19. Christensen BC, Houseman EA, Marsit CJ, Zheng S, Wrensch MR, Wiemels JL, Nelson $\mathrm{HH}$, Karagas MR, Padbury JF, Bueno R, et al. Aging and environmental exposures alter tissue-specific DNA methylation dependent upon CpG island context. PLoS Genet. 2009:5(8):e1000602.

20. Alisch RS, Barwick BG, Chopra P, Myrick LK, Satten GA, Conneely KN, Warren ST. Age-associated DNA methylation in pediatric populations. Genome Res. 2012:22(4):623-32

21. Bork S, Pfister S, Witt H, Horn P, Korn B, Ho AD, Wagner W. DNA methylation pattern changes upon long-term culture and aging of human mesenchymal stromal cells. Aging Cell. 2010;9(1):54-63.

22. Horvath S. DNA methylation age of human tissues and cell types. Genome Biol. 2013;14(10):R115.

23. Steegenga WT, Boekschoten MV, lute C, Hooiveld GJ, de Groot PJ, Morris TJ, Teschendorff AE, butcher LM, Beck S, Muller M. genome-wide age-related 
changes in DNA methylation and gene expression in human PBMCs. Age (Dordr). 2014;36(3):9648.

24. Hannum G, Guinney J, Zhao L, Zhang L, Hughes G, Sadda S, Klotzle B, Bibikova M, Fan JB, Gao Y, et al. Genome-wide methylation profiles reveal quantitative views of human aging rates. Mol Cell. 2013;49(2):359-67.

25. Pidsley R, CC YW, Volta M, Lunnon K, Mill J, Schalkwyk LC. A data-driven approach to preprocessing Illumina $450 \mathrm{~K}$ methylation array data. BMC Genomics. 2013;14:293.

26. Yousefi P, Huen K, Aguilar Schall R, Decker A, Elboudwarej E, Quach H, Barcellos L, Holland N. Considerations for normalization of DNA methylation data by Illumina 450K BeadChip assay in population studies. Epigenetics. 2013;8(11):1141-52.

27. Du P, Kibbe WA, Lin SM. Lumi: a pipeline for processing Illumina microarray Bioinformatics. 2008;24(13):1547-8.

28. Sun Z, Chai HS, Wu Y, White WM, Donkena KV, Klein CJ, Garovic VD, Therneau $T M$, Kocher JP. Batch effect correction for genome-wide methylation data with Illumina Infinium platform. BMC Med Genet. 2011:4:84

29. Sandoval J, Heyn H, Moran S, Serra-Musach J, Pujana MA, Bibikova M, Esteller M. Validation of a DNA methylation microarray for $450,000 \mathrm{CpG}$ sites in the human genome. Epigenetics. 2011;6(6):692-702.

30. Nordlund J, Backlin CL, Wahlberg P, Busche S, Berglund EC, Eloranta ML, Flaegstad T, Forestier E, Frost BM, Harila-Saari A, et al. Genome-wide signatures of differential DNA methylation in pediatric acute lymphoblastic leukemia. Genome Biol. 2013;14(9):r105.

31. Guo JU, Ma DK, Mo H, Ball MP, Jang MH, Bonaquidi MA, Balazer JA, Eaves $\mathrm{HL}$, Xie B, Ford E, et al. Neuronal activity modifies the DNA methylation landscape in the adult brain. Nat Neurosci. 2011;14(10):1345-51.

32. Falcon S, Gentleman R. Using GOstats to test gene lists for GO term association. Bioinformatics. 2007;23(2):257-8.

33. Garagnani P, Bacalini MG, Pirazzini C, Gori D, Giuliani C, Mari D, Di Blasio AM, Gentilini D, Vitale G, Collino S, et al. Methylation of ELOVL2 gene as a new epigenetic marker of age. Aging Cell. 2012;11(6):1132-4.

34. Bacalini MG, Deelen J, Pirazzini C, De Cecco M, Giuliani C, Lanzarini C, Ravaioli F, Marasco E, van Heemst D, Suchiman HE, et al. Systemic ageassociated DNA Hypermethylation of ELOVL2 gene: in vivo and in vitro evidences of a cell replication process. J Gerontol A Biol Sci Med Sci. 2016;

35. Ding Y, He F, Wen H, Li J, Ni M, Chi M, Qian K, Bu Y, Zhang D, Si Y, et al. DNA methylation status of cyp17-II gene correlated with its expression pattern and reproductive endocrinology during ovarian development stages of Japanese flounder (Paralichthys Olivaceus). Gene. 2013;527(1):82-8.

36. Jones MJ, Islam SA, Edgar RD, Kobor MS. Adjusting for cell type composition in DNA methylation data using a regression-based approach. Methods Mol Biol. 2017;1589:99-106.

37. Yamamoto H, Tsukahara K, Kanaoka Y, Jinno S, Okayama H. Isolation of a mammalian homologue of a fission yeast differentiation regulator. Mol Cell Biol. 1999; 19(5):3829-41.

38. Maniatis T, Tasic B. Alternative pre-mRNA splicing and proteome expansion in metazoans. Nature. 2002;418(6894):236-43.

39. Spellman R, Llorian M, Smith CW. Crossregulation and functional redundancy between the splicing regulator PTB and its paralogs $\mathrm{nPTB}$ and ROD1. Mol Cell. 2007:27(3):420-34.

40. Sadvakassova G, Dobocan MC, Difalco MR, Congote LF. Regulator of differentiation 1 (ROD1) binds to the amphipathic C-terminal peptide of thrombospondin-4 and is involved in its mitogenic activity. J Cell Physiol. 2009:220(3):672-9.

41. Meissner TB, Li A, Liu YJ, Gagnon E, Kobayashi KS. The nucleotide-binding domain of NLRC5 is critical for nuclear import and transactivation activity. Biochem Biophys Res Commun. 2012;418(4):786-91.

42. Staehli F, Ludigs K, Heinz LX, Seguin-Estevez Q, Ferrero I, Braun M, Schroder K, Rebsamen M, Tardivel A, Mattmann C, et al. NLRC5 deficiency selectively impairs MHC class I- dependent lymphocyte killing by cytotoxic T cells. J Immunol. 2012;188(8):3820-8.

43. Rodriguez GM, Bobbala D, Serrano D, Mayhue M, Champagne A, Saucier C, Steimle V, Kufer TA, Menendez A, Ramanathan S, et al. NLRC5 elicits antitumor immunity by enhancing processing and presentation of tumor antigens to CD8(+) T lymphocytes. Oncoimmunology. 2016;5(6):e1151593.

44. Liu B, Park E, Zhu F, Bustos T, Liu J, Shen J, Fischer SM, Hu Y. A critical role for I kappaB kinase alpha in the development of human and mouse squamous cell carcinomas. Proc Natl Acad Sci U S A. 2006;103(46):17202-7.
45. Pannicke U, Baumann B, Fuchs S, Henneke P, Rensing-Ehl A, Rizzi M, Janda A, Hese K, Schlesier M, Holzmann K, et al. Deficiency of innate and acquired immunity caused by an IKBKB mutation. N Engl J Med. 2013;369(26):2504-14.

46. Cui J, Zhu L, Xia X, Wang HY, Legras X, Hong J, Ji J, Shen P, Zheng S, Chen ZJ, et al. NLRC5 negatively regulates the NF-kappaB and type I interferon signaling pathways. Cell. 2010;141(3):483-96.

47. Yoshihama S, Vijayan S, Sidiq T, Kobayashi KS. NLRC5/CITA: a key player in cancer immune surveillance. Trends Cancer. 2017;3(1):28-38.

48. Yoshihama S, Roszik J, Downs I, Meissner TB, Vijayan S, Chapuy B, Sidiq T, Shipp MA, Lizee GA, Kobayashi KS. NLRC5/MHC class I transactivator is a target for immune evasion in cancer. Proc Natl Acad Sci U S A. 2016;113(21): 5999-6004.

49. Ruppert JM, Kinzler KW, Wong AJ, Bigner SH, Kao FT, Law ML, Seuanez HN, O'Brien SJ, Vogelstein B. The GLI-Kruppel family of human genes. Mol Cell Biol. 1988:8(8):3104-13.

50. Oguri T, Katoh O, Takahashi T, Isobe T, Kuramoto K, Hirata S, Yamakido M, Watanabe $\mathrm{H}$. the Kruppel-type zinc finger family gene, HKR1, is induced in lung cancer by exposure to platinum drugs. Gene. 1998;222(1):61-7.

51. Teschendorff AE, Zheng SC. Cell-type deconvolution in epigenome-wide association studies: a review and recommendations. Epigenomics. 2017;9(5): 757-68.

52. Jaffe AE, Irizarry RA. Accounting for cellular heterogeneity is critical in epigenome-wide association studies. Genome Biol. 2014;15(2):R31.

53. McEwen LM, Morin AM, Edgar RD, Maclsaac JL, Jones MJ, Dow WH, Rosero-Bixby L, Kobor MS, Rehkopf DH. Differential DNA methylation and lymphocyte proportions in a costa Rican high longevity region. Epigenetics Chromatin. 2017;10:21.

\section{Submit your next manuscript to BioMed Central and we will help you at every step:}

- We accept pre-submission inquiries

- Our selector tool helps you to find the most relevant journal

- We provide round the clock customer support

- Convenient online submission

- Thorough peer review

- Inclusion in PubMed and all major indexing services

- Maximum visibility for your research

Submit your manuscript at www.biomedcentral.com/submit
C Biomed Central 